\title{
Soil vapor extraction of wet gasoline-contaminated soil made possible by electroosmotic dewatering-lab simulations applied at a field site
}

\author{
Suvi Simpanen ${ }^{1}$ Dan Yu $^{1}$ • Riikka Mäkelä ${ }^{1}$ Harri Talvenmäki ${ }^{1}$ - Aki Sinkkonen ${ }^{1}$ \\ Hannu Silvennoinen ${ }^{2}$ Martin Romantschuk ${ }^{1,3}$
}

Received: 18 November 2016/Accepted: 25 April 2017 /Published online: 4 May 2017

(C) The Author(s) 2017. This article is an open access publication

\begin{abstract}
Purpose Soil restoration is still mainly carried out ex situ by excavating and replacing the contaminated soil. In situ remediation would reduce the costs of soil transportation and this way, the problem is not merely transferred elsewhere. The present study introduces a field case where the aged, oilcontaminated soil in a former fuel station in Finland was treated in situ sequentially with different methods.

Materials and methods Several approaches, including soil vapor extraction and biostimulation with electrokinetic pumping, were performed in the field. After these treatments, the dense original portion of the soil beneath the gasoline pump location, ca $100 \mathrm{~m}^{3}$, was still contaminated with petroleum-derived volatile organic compounds (VOCs), with concentrations of nearly $10,000 \mathrm{mg} \mathrm{kg}^{-1}$ measured at some hotspots. After a period of electroosmotic water circulation, the electrical field $\left(0.5 \mathrm{~V} \mathrm{~cm}^{-1}\right.$, DC) was kept connected for 6 months without addition of water, leading to dewatering and warming of the soil.

Results and discussion In contrast to the situation with the original wet soil, VOCs, in lab conditions, were found to
\end{abstract}

Responsible editor: Xilong Wang

Electronic supplementary material The online version of this article (doi:10.1007/s11368-017-1717-1) contains supplementary material, which is available to authorized users.

Martin Romantschuk

martin.romantschuk@helsinki.fi

1 Department of Environmental Sciences, University of Helsinki, Niemenkatu 73, 15140 Lahti, Finland

2 Nordic Envicon Ltd, Huopalahdentie 24, 00350 Helsinki, Finland

3 Institute of Environmental Sciences, Kazan Federal University, Kazan, Russia 420008 volatilize very efficiently from the dewatered soil. When the soil vapor extraction treatment was renewed using perforated tubing installed horizontally at ca $1 \mathrm{~m}$ depth in the dewatered soil at the contaminated site, the treatment was efficient and the soil was decontaminated in 5 months. The final VOC concentrations were on average $190 \mathrm{mg} \mathrm{kg}^{-1}(n=13)$ with the highest value of $700 \mathrm{mg} \mathrm{kg}^{-1}$ at one hotspot. After a risk evaluation, the site was concluded to be sufficiently clean for industrial use. Conclusions Since with many former fuel stations, the contamination consists of both volatile fractions that are difficult to degrade by biological means and heavier compounds for which biostimulation is often suitable, a combination of different methods may be worth pursuing.

Keywords Oil hydrocarbon contamination · Soil remediation $\cdot$ Electrokinetic remediation

\author{
Abbreviations \\ BTEX Benzene, toluene, ethylbenzene, and xylenes \\ PHCs Petroleum hydrocarbons \\ SVE Soil vapor extraction \\ VOCs Volatile organic compounds
}

\section{Introduction}

The soil at most if not all old fuel stations in Finland is contaminated with gasoline, diesel fuel, and other petroleum hydrocarbons (PHCs) (Pyy et al. 2013). Even normal fuel station practices result in small repeating discharges of fuel and lubricating oil that when infiltrated into the soil may result in high contaminant levels, posing a threat to the ground water and the local environment in general (Puolanne et al. 1994). Because of the low soil temperature in Finland and similar regions, 
natural attenuation does not remove the oil with sufficient velocity (Romantschuk et al. 2000), even if the natural microbial community has the capacity to perform the degradation (Kauppi et al. 2011). Diesel fuel is biologically readily degraded when bottlenecks for microbial activity-low temperature, lack of nutrients, etc.- - are removed (Kauppi et al. 2011). Although BTEX (benzene, toluene, ethylbenzene, and xylenes) compounds, aromatic components of gasoline, are biodegradable, the removal efficiency is lower than for many of the aliphatic diesel fuel components (Soares et al. 2010; Soares et al. 2012). On the other hand, BTEX compounds are volatile and, similarly to the Volatile organic compounds (VOCs), can be easily removed by soil vapor extraction (SVE) if the conditions are suitable (Farhan et al. 2001; Boudouch et al. 2012). The SVE does not work well in wet or otherwise impermeable soil (Garcia-Gerruzo et al. 1994; Farhan et al. 2001) and is considerably slower in cold than in warm conditions (GarciaGerruzo et al. 1994; Huon et al. 2012). Here, we describe an approach where electroosmotic treatment of the soil at a former fuel station resulted in warming and dewatering of the contaminated soil, from which gasoline-derived VOC compounds then could be efficiently removed by SVE.

\section{Materials and methods}

\subsection{Site description and electrokinetic remediation}

The site was a former fuel station in the Jalasjärvi municipality (coordinates, N6235, E2284) that had been in use from the late 1950s until the beginning of 1990s. In the middle of 2000s, the contamination levels were such that active cleaning of the site was demanded by authorities. The contaminated area was $5 \mathrm{~m}$ wide and $6 \mathrm{~m}$ long, with the contaminants, mostly heterogeneously distributed $\mathrm{C}_{6}-\mathrm{C}_{10}$ residues, peaking at 3000 $4000 \mathrm{~m} \mathrm{~kg}^{-1}$. Maximum depth of the contaminated volume was $6 \mathrm{~m}$. The soil directly beneath the location of the former fuel pumps was course sand that had been introduced during construction of the station, but beneath a depth of $1.5 \mathrm{~m}$, under a layer of Styrofoam plates, the natural soil was dense wet silty soil. The first remediation effort was started in 2006 using SVE for 8 months but the treatment had been found ineffective by regular photoionization detector (PID) monitoring of the extracted air. Electroremediation-based soil cleaning was started in autumn 2007. First, stainless steel rods $(1 \mathrm{~cm}$ in diameter) were installed as electrodes in drilled holes inside perforated plastic tubes down to a depth of 5 to $6 \mathrm{~m}$. A row of four anodes was installed in parallel at ca. $2 \mathrm{~m}$ intervals, and a row of cathodes was installed in a similar manner $5 \mathrm{~m}$ from the anode row (Fig. 1). Anodes and cathodes, respectively, were connected in parallel with copper cable to a transformer serving as a power supply and set to $270 \mathrm{~V} \mathrm{DC}$ resulting in a voltage of ca. $0.54 \mathrm{~V} \mathrm{~cm}^{-1}$. The maximum current capacity of the transformer was $40 \mathrm{~A}$, which clearly exceeded the maximum current recorded at the site.

At initial stages of the in situ treatment, water amended with nutrients had been infiltrated via the anode cavities and from the top through holes in the asphalt. The top layer of course sand was decontaminated during this treatment from all PHC components, while the deeper layers consisting of dense natural soil was still found to be heavily contaminated with VOC components. The period of biostimulation was followed by continued electrokinetic treatment for 6 months during the winter but with no addition of liquids. After the discontinuation of addition of water, the electricity consumption fell first rapidly from the maximum level of $7 \mathrm{~A}(1.9 \mathrm{~kW})$ within 1 day to $2 \mathrm{~A}(540 \mathrm{~W})$ and then gradually to a level below $0.5 \mathrm{~A}(135 \mathrm{~W})$ when the treatment was discontinued. When soil samples were collected in December 2008 (after a 2-month period of electrokinetic drying), the soil was warm and dry at all depths influenced by the electric field. The consumption of electricity for the total site treatment including the circulation of nutrient-rich water and the dewatering phase was about 20,000 kWh leading to expenses of less than 1000 $€$. The dewatering phase of the electrokinetic treatment consumed less than $1000 \mathrm{kWh}$ costing less than $50 €$.

\subsection{Laboratory simulation}

Laboratory scale VOC evaporation test was performed with contaminated soil taken from 1.5-2.0 m depth of the Jalasjärvi site after the electrokinetic drying. The volume of $0.5 \mathrm{~L}$ glass bottles was filled with $800 \mathrm{~g}$ of soil. The mass was assumed to correlate positively with the VOC removal time. The soil density achieved was still assumed to be lower than in the field, so that spontaneous evaporation in the flasks roughly would reflect SVE in the field. The soils were wetted to the saturation degree of $0 \%$ (equal to electrokinetically dried soil, no water added) 40,70 , or $100 \%$ saturated with water). Each saturation degree was tested as three replicates. Saturation degree was kept constant by following the mass of soil and adding water when needed. A capped bottle with soil of $0 \%$ saturation degree was included as a control. Bottles were placed in a fume hood at ambient temperature of $+18{ }^{\circ} \mathrm{C}$ and incubated for 9 weeks. The VOCs were recorded with a PID by closing the bottle with a parafilm for 1 hour, after which the air space of the bottle was measured. Measurements were done 32 times during the 9-week incubation period. Hydrocarbon $\mathrm{C}_{5}-\mathrm{C}_{10}$ concentrations (including BTEX compounds) were analyzed from the soil samples $(100 \mathrm{~g})$ at the start of the experiment and after 3 and 9 weeks of incubation.

\subsection{Soil vapor extraction field treatment}

Based on the result of lab simulation, the SVE treatment was started in the field again. A trench $(1.5 \mathrm{~m}$ depth, $5 \mathrm{~m}$ length, 
and $0.4 \mathrm{~m}$ width) was dug with the narrow scoop of a front loader for installation of SVE tubing so that it was located ca. $20 \mathrm{~cm}$ into the dense-contaminated soil. The perforated 50$\mathrm{mm}$ SVE tube was installed at the bottom of the trench and hooked up to a vacuum pump via sealed plastic tubing. The tubing at the bottom of the trench was covered with a plastic sheet and sand in order to direct the vacuum effect downwards. The extracted vapors were collected in activated charcoal before release of the cleaned soil air. Approximate vapor PHC concentrations were monitored with a handheld PID analyzer. When concentrations based on PID analyses had dropped significantly, the soil was sampled down to a depth of $5 \mathrm{~m}$ at all previously identified hotspots. The total time for SVE pumping was 5 months, the pumping power being $100 \mathrm{~m}^{3} / \mathrm{h}$.

\subsection{Sampling}

Soil core samples $(10 \mathrm{~cm}$ in diameter) were taken by the Destia Ltd. with a drilling machine down to a depth of $6 \mathrm{~m}$. At each sampling, soil cores were taken from the four sampling points in the area of contamination (Fig. 1) and two controls outside the area. Soil columns were divided into roughly $0.5-1-\mathrm{m}$ sections for further analysis. Samples were also taken from the ground water beneath the contaminated soil and downstream of the site. In the field, thorough sampling for VOC analyses was done three times, after electrokinetic enhanced biostimulation and electrokinetic drying on

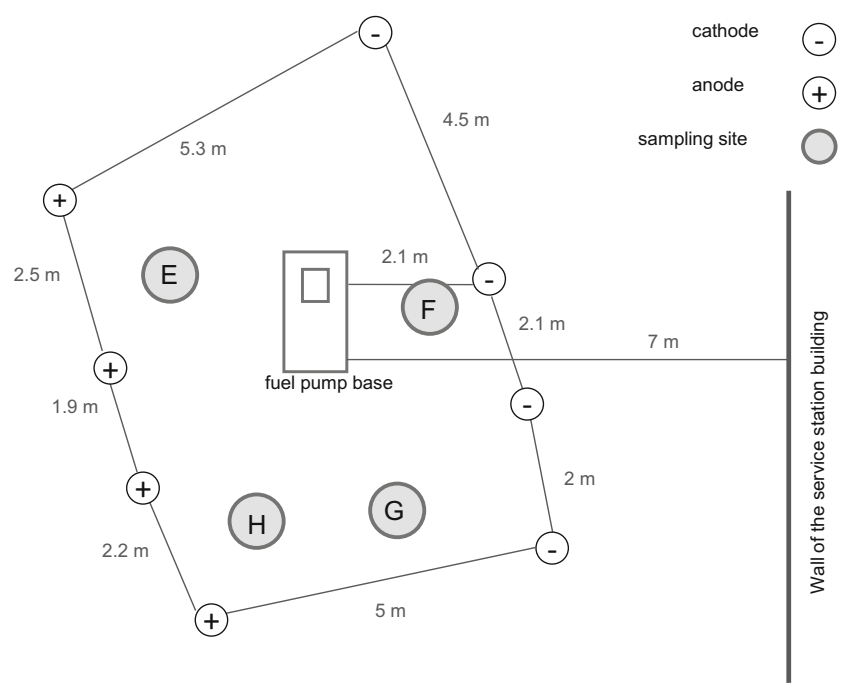

Fig. 1 Top view of the treated fuel station area. The rows of anodes and cathodes are indicated. The contaminated area lies between these rows and extends down to $5 \mathrm{~m}$ below ground. The central part beneath the concrete fuel pump base (rectangle in the middle) consisted of ca $20 \mathrm{~m}^{3}$ of course sand down to $1.5 \mathrm{~m}$ below ground. This section (ca $4 \times 3.5 \mathrm{~m}$ ) was readily infiltrated by nutrient-rich water introduced to achieve biostimulation. The rest of the $200 \mathrm{~m}^{3}$ polluted soil was dense natural soil. The capital letters indicate sections where initial sampling had recorded high concentrations of TPH
December 2008 and after electrokinetic drying and soil vapor extraction on August 2009 and at the end of treatments on October 2009 (Table 1).

\subsection{Physical and chemical analyses}

Temperature of the soil was recorded immediately after soil lifting. Dry matter content was determined by drying 2-6 g soil sample overnight at $105^{\circ} \mathrm{C}$ and the organic matter content was measured as loss on ignition $\left(4 \mathrm{~h}\right.$ in $\left.550{ }^{\circ} \mathrm{C}\right)$. VOCs, including the total $\mathrm{C}_{5}-\mathrm{C}_{10}$ fractions, BTEX compounds, and oxygenates (MTBE, TAME), were analyzed with a method based on standards EPA Method 8260B, EPA Method 5021, and ISO/DIS 22155. Analysis was done using methanol extraction and determination was done with a static headspace technique using gas chromatography/mass spectrometry (HS/ GC/MS). Total $\mathrm{C}_{10}-\mathrm{C}_{40}$ fractions were analyzed according to standards ISO16703 using hexane-acetone extraction and gas chromatography/flame ionization detector. Analyses were performed at Ramboll Analytics Ltd. in Lahti, Finland.

\subsection{Statistical methods}

Univariate analysis of variance with Tukey's post hoc tests was used to analyze the data in IBM SPSS Statistics $23 . \mathrm{C}_{5}$ $\mathrm{C}_{10}$ concentrations $\left(\mathrm{mg} \mathrm{kg}^{-1}\right)$ in soil were analyzed on week 3 and week 9. Volatile organic compounds in the air ( $\mathrm{ppm}$ ) were analyzed first as single-day PID values on days 0,1 , and 3 to distinguish differences in the rapid volatilization of the most volatile low molecular weight compounds. Thereafter, differences in the cumulative values of PID measurements were compared between different treatments. The first cumulative PID period preceded the second oil hydrocarbon measurement (days 7-21, PID values were measured every third day) and the second PID period covered days 23-75. As PID values in closed bottles are not comparable with those in open bottles and as PID values in the closed control bottles stayed at 0 day values over the whole experimental period, the treatment was excluded for the PID analysis.

\section{Results and discussion}

In this study, the soil at a former fuel station was treated with a set of in situ methods in order to remove PHC derived from gasoline, diesel fuel, and lubricating oil that had seeped into the soil during decades of normal use with no major accidents recorded. First treatment with SVE had been found nonfunctional in the initially wet untreated soil presumably since VOCs are less volatile in wet conditions (data not shown). Electrokinetically enhanced biostimulation, using methods described for PAHs by Suni et al. (2007), removed efficiently diesel compounds (initial $\mathrm{C}_{10}-\mathrm{C}_{40}$ concentration ca. 
Table 1 Hydrocarbon $\mathrm{C}_{5}-\mathrm{C}_{10}$ and $\mathrm{C}_{10}-\mathrm{C}_{40}$ concentrations in samples taken from the fuel station site. SVE treatment started in May 2009

\begin{tabular}{|c|c|c|c|c|c|}
\hline $\begin{array}{l}\text { Sampling } \\
\text { time }\end{array}$ & $\begin{array}{l}\text { Treatments } \\
\text { before sampling }\end{array}$ & $\begin{array}{l}\text { Sampling } \\
\text { site }\end{array}$ & $\begin{array}{l}\text { Sampling } \\
\text { epth }\end{array}$ & $\begin{array}{l}\mathrm{C}_{5}-\mathrm{C}_{10} \mathrm{mg} \\
\mathrm{kg}^{-1}\end{array}$ & $\begin{array}{l}\mathrm{C}_{10}-\mathrm{C}_{40} \mathrm{mg} \\
\mathrm{kg}^{-1}\end{array}$ \\
\hline \multirow{15}{*}{$\begin{array}{l}\text { December } \\
2008\end{array}$} & \multirow{15}{*}{$\begin{array}{l}\text { Biostimulation with } \\
\text { electrokinetic } \\
\text { pumping for } 1 \text { year, } \\
\text { electrokinetic drying } \\
\text { for } 2 \text { months }\end{array}$} & \multirow[t]{3}{*}{ E } & $0.5-1.5 \mathrm{~m}$ & 49 & 91 \\
\hline & & & $1.5-2.5 \mathrm{~m}$ & 9000 & 474 \\
\hline & & & $2.5-3.5 \mathrm{~m}$ & 2300 & 50 \\
\hline & & \multirow[t]{5}{*}{$\mathrm{F}$} & $0.5-1.5 \mathrm{~m}$ & 61 & 63 \\
\hline & & & $1.5-2.5 \mathrm{~m}$ & 8700 & 339 \\
\hline & & & $2.5-3.5 \mathrm{~m}$ & 3400 & 124 \\
\hline & & & $3.5-4.5 \mathrm{~m}$ & 660 & 31 \\
\hline & & & $4.5-5.5 \mathrm{~m}$ & 40 & 8 \\
\hline & & \multirow[t]{4}{*}{ G } & $0.5-1.5 \mathrm{~m}$ & 45 & 19 \\
\hline & & & $1.5-2.5 \mathrm{~m}$ & 4800 & 80 \\
\hline & & & $2.5-3.5 \mathrm{~m}$ & 110 & 23 \\
\hline & & & $3.5-4.5 \mathrm{~m}$ & 8.1 & 5 \\
\hline & & \multirow[t]{3}{*}{$\mathrm{H}$} & $0.5-1.5 \mathrm{~m}$ & 27 & 38 \\
\hline & & & $1.5-2.5 \mathrm{~m}$ & 350 & 43 \\
\hline & & & $2.5-3.5 \mathrm{~m}$ & 0.5 & 7 \\
\hline \multirow[t]{6}{*}{ August 2009} & \multirow{6}{*}{$\begin{array}{l}\text { Electrokinetic drying for } \\
4 \text { months, soil vapor } \\
\text { extraction for } \\
2 \text { months }\end{array}$} & \multirow[t]{2}{*}{ E } & $1.2 \mathrm{~m}$ & 8.6 & \\
\hline & & & $1.5 \mathrm{~m}$ & 8000 & \\
\hline & & \multirow[t]{2}{*}{$\mathrm{F}$} & $0.8-1 \mathrm{~m}$ & $31-67$ & \\
\hline & & & $1.5 \mathrm{~m}$ & 590 & \\
\hline & & \multirow[t]{2}{*}{$\mathrm{H}$} & $1.2 \mathrm{~m}$ & 150 & \\
\hline & & & $1.4 \mathrm{~m}$ & 26,000 & \\
\hline \multirow{11}{*}{$\begin{array}{c}\text { October } \\
2009\end{array}$} & \multirow{11}{*}{$\begin{array}{l}\text { Soil vapor extraction for } \\
\text { extra months }\end{array}$} & \multirow[t]{3}{*}{$\mathrm{E}$} & $0.1-1.2 \mathrm{~m}$ & 400 & \\
\hline & & & $2.1-2.4 \mathrm{~m}$ & 460 & \\
\hline & & & $2.6-3.2 \mathrm{~m}$ & 8 & \\
\hline & & \multirow[t]{4}{*}{$\mathrm{F}$} & $1-1.4 \mathrm{~m}$ & 5 & \\
\hline & & & $1.4-1.6 \mathrm{~m}$ & 5 & \\
\hline & & & $2-2.8 \mathrm{~m}$ & 5 & \\
\hline & & & $2.8-3.4 \mathrm{~m}$ & 5 & \\
\hline & & \multirow[t]{4}{*}{$\mathrm{G}-\mathrm{H}$} & $0.8-1.4 \mathrm{~m}$ & 640 & \\
\hline & & & $1.8-2.2 \mathrm{~m}$ & 700 & \\
\hline & & & $2.2-2.8 \mathrm{~m}$ & 7 & \\
\hline & & & $2.8-3.4 \mathrm{~m}$ & 280 & \\
\hline
\end{tabular}

$2700 \mathrm{mg} \mathrm{kg}^{-1}$ before the start of biostimulation) but had very little effect on gasoline-derived VOCs in the natural dense soil beneath the installation (Table 1). During the liquid circulation soil moisture was ca. $15 \%$ and a maximum current of 7 A was recorded, but mostly, 1.0-2.0 A was in use. As the electroosmotic pumping was continued at $270 \mathrm{~V}$ without addition of water, the current dropped to below $0.5 \mathrm{~A}$ where it remained for 6 months, over the winter in 2008-2009. Apparently, this was due to low conductivity in the dry soil. The area was sampled in December 2008 and found still to be heavily contaminated with hydrocarbons $\mathrm{C}_{5}-\mathrm{C}_{10}$ in hot spots within the dense soil regions (Table 1.), but as opposed to earlier observations, the soil moisture had dropped to 5-8\%. At that time, the soil temperature was $15-20^{\circ} \mathrm{C}$ below the depth of $1.5 \mathrm{~m}$, and a strong smell of gasoline could be observed, whereas no such smell was observed with the same soil using the earlier, wet samples. This was likely the result of increased VOC volatilization from the dried soil, which gave us the idea to test hydrocarbon evaporation at different soil moisture levels.

Evaporation experiments in lab conditions were performed with dried soil and with a set of soils wetted to different levels, one of the levels representing the original moisture level. A clear difference between soils with different moisture levels was observed in the recorded PID values from the head space of the flasks after day 0 . On day 0, PID values were equal in all treatments (Fig. 2a; mean $\pm \mathrm{SE}=965 \pm 29 ; F=3.6, \mathrm{df}=3,8$, $p>0.05)$. The capped control retained a high PID value of over 1000 ppm, while very low PID values were observed in 
Fig. 2 Volatile organic carbon (VOC) concentrations in the laboratory experiment measured from a the air space of the bottle with the photoionization detector and from $\mathbf{b}$ the soil samples (mean \pm SD) taken at the start of the experiment and after 3 and 9 weeks of incubation. Soil water content is shown as percentages of saturation degree $(100 \%$ is saturated with water and $0 \%$ without water amendment, equal to electrokinetically dried soil). In b, letters indicate homogenous subsets in Tukey's post hoc tests
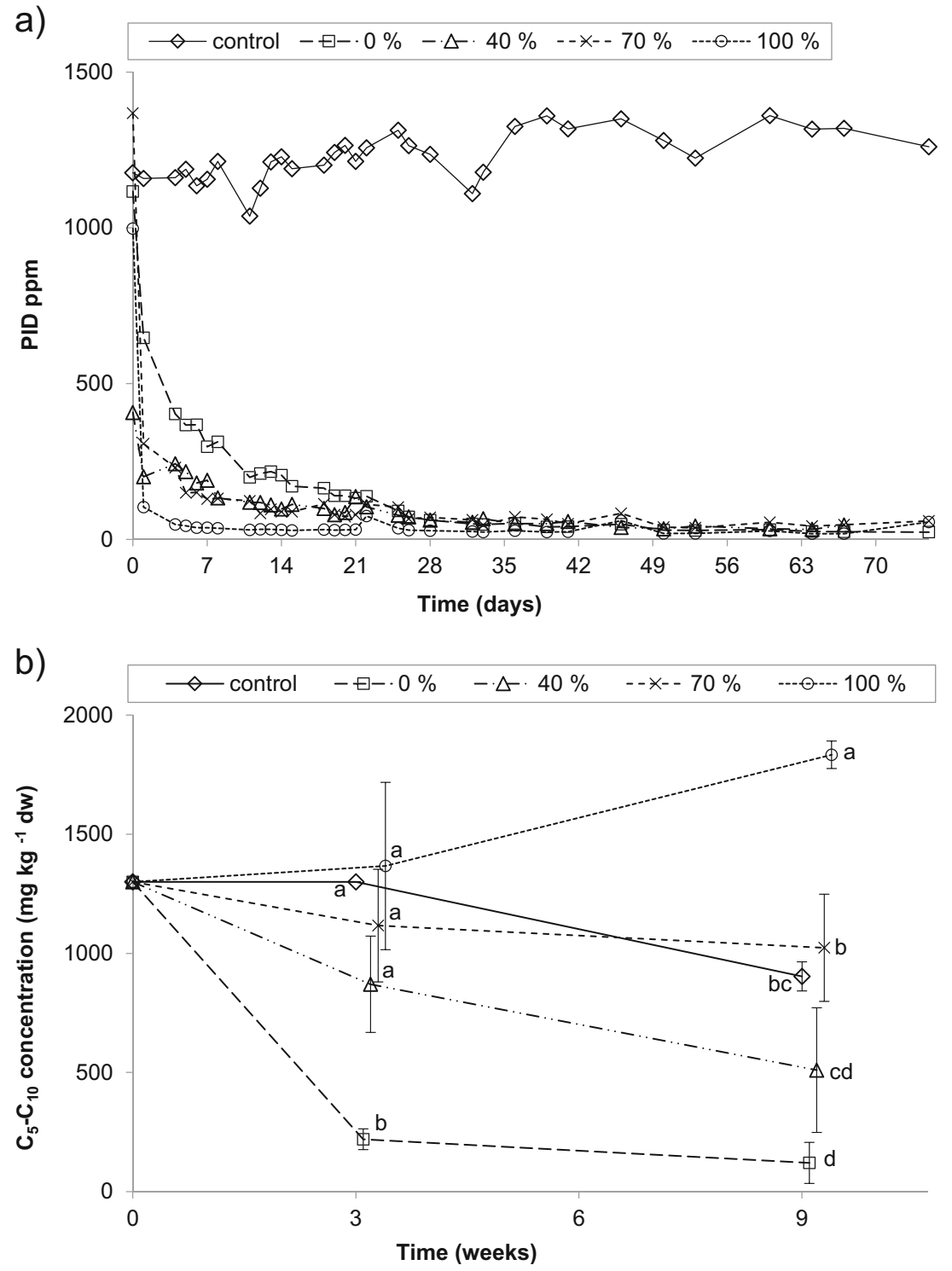

the $100 \%$ saturation degree flasks (Fig. 2a). The dried, field moisture soil ( $0 \%$ saturation degree) flask produced higher VOC vapors for the first 22 days, while the soil of 40 and $70 \%$ levels of saturation degree was found between the extremes (Fig. 2a). In more detail, on days 1 and 3, PID values dropped steadily in all noncapped treatments (Fig. 2a) and values in the dried, field moisture soil ( $0 \%$ saturation degree) were higher than those in the $100 \%$ saturation degree treatment ( $F \geq 8.3, \mathrm{df}=3,8, p \leq 0.018$ ). On days $7-21$, the cumulative PID value was the highest at $0 \%$ saturation degree treatment and the lowest in the $100 \%$ saturation degree treatment (Fig. S1a in the Electronic Supplementary Material, $F=75.8$, $\mathrm{df}=3,8, p<0.0005)$. After a 23-day incubation the VOC concentration in the head space was very low in all flasks except the capped control. On days 23-75, the cumulative PID value was smaller in the $100 \%$ saturation degree treatment than in 40 and $70 \%$ saturation degree treatments, and the $0 \%$ saturation degree treatment (open bottles) was not different from any other treatment (Fig. S1b in the Electronic Supplementary Material, $F=6.6, \mathrm{df}=3,8, p=0.015$ ).

As gasoline concentrations in soil were equal on day 0 , we compared the concentrations on weeks 3 and 9 (Fig. 2b). On week 3, gasoline concentration in soil was lower in $0 \%$ saturation degree treatment (open bottles) than in the other treatments (Fig. 2b; $F=14.5$, df $=4,10, p<0.0005$ ). The other saturation level treatments had similar concentrations $(p>0.05)$. On week 9, gasoline concentration was the lowest in the $0 \%$ saturation degree treatment and the highest in $100 \%$ saturation degree treatment (Fig. $2 \mathrm{~b} ; F=46.2$, df $=4,10$, $p<0.0005)$. The results indicate that the lower the saturation degree is, the faster is the evaporation of gasoline compounds from soil. Combined with PID results, we report that gasoline compounds evaporated to a significant degree and that the evaporation was enhanced in dry conditions. 
The lab experience was applied to the field conditions starting in May 2009. At this point, the electrokinetic treatment was stopped and SVE tubing was installed as described in Section 2.3. The approximate VOC concentration in the vapors pumped from the ground was monitored biweekly using a handheld PID device before and after the air passed through an activated charcoal filter (data not shown). The SVE treatment was stopped at the end of October 2009 and the area, including previous hot spots, was sampled (Table 1). The soil temperature was still on average $18^{\circ} \mathrm{C}$ at the depth of the tubing, but the VOC odors were almost indistinguishable. The samples were shown to have residues of $\mathrm{C}_{5}-\mathrm{C}_{10}$ PHCs that were below the required target concentrations (higher guideline value for industrial use $500 \mathrm{mg} \mathrm{kg}^{-1}$ ) at most of the sampled spots (Table 1). Since some fractions were found in concentrations above the target value, a site-specific risk assessment was performed quantitatively with the SOILIRISK model. With no changes in land use, the site was found to be in acceptable condition requiring neither further remediative actions nor monitoring.

The sequential approach towards achieving in situ remediation had thus led to the desired result. In this process, the method development and technical modeling in the lab were crucial, both for understanding the phenomena observed and for a proper application of the methods developed. The total treatment time at the site was rather long-over 2 years-but a great portion of this time could have been saved with a more systematic use of lab pretesting, in particular at the onset of the treatment. The efficient and active phases of the treatment represented about half of the total time, and based on experience gained at Jalasjärvi and other typical former fuel station sites, similar new cases could be treated in a substantially shorter time, using the best suited combination of methods in an optimal order.

Investments in equipment had been done earlier, before the Jalasjärvi project and during the biostimulation phase of the project. Costs connected specifically to the dewatering and SVE phase reported here are the electricity consumption during the electrokinetic dewatering and the SVE vacuum pumping. The electricity price during the time of these treatments fluctuated around $0.09 € \mathrm{kWh}^{-1}$ and is still comparable to that level, although the fluctuations are wider now. Calculating with an average power $135 \mathrm{~W}(270 \mathrm{~V}, 0.5 \mathrm{~A})$ and a treatment time of 9 months, the estimated total electricity consumption during the dewatering phase was ca $1400 \mathrm{kWh}$ costing ca $130 €$. The electricity consumption by the vacuum pump running for 3 months raises the total price for the electricity to ca $200 €$. Sampling, analyzing, and installing of the perforated SVE tubing generated far more expenses than the soil dewatering and SVE activities. The volume of the treated soil was approximately $130 \mathrm{~m}^{3}$ taking into account the depth from $1.5 \mathrm{~m}$ below ground down to $6 \mathrm{~m}$ below ground and assuming that the area influenced by the electrokinetic dewatering was the area between the rows of electrodes. All soil above the $1.5 \mathrm{~m}$ depth had been cleaned previously. This should be compared to the volume $180 \mathrm{~m}^{3}$ $(6 \times 5 \times 6 \mathrm{~m})$ in case of using excavation; since then, also the cleaned top layer would have been removed. In addition, such excavation would also have required removal of the constructions on top of the ground.

\section{Conclusions}

In all, a novel combination of existing methods for in situ remediation of soil contaminated with volatile recalcitrant substances is presented. Once the methods were applied in correct sequence, light fraction PHC components including BTEX were readily removed in a cost-efficient manner. Based on the experience gathered here, the remediation of similar sites can be planned to be executed in less than 1 year, at total costs that are competitive with excavation and other more invasive procedures. It is envisioned that other volatile water-insoluble compounds could be removed in a similar manner and that sites larger in area could be treated with similar sequence of methods, although compound properties and site-specific matters have to be taken into account.

Acknowledgments This work was supported by Tekes - the Finnish Funding Agency for Innovation. Additional funding was obtained from the Finnish Cultural Foundation's Päijät-Häme Regional Fund and via the EU Baltic Central project INSURE. The Jalasjärvi Voluntary Fire Brigade is acknowledged for technical help.

Open Access This article is distributed under the terms of the Creative Commons Attribution 4.0 International License (http:// creativecommons.org/licenses/by/4.0/), which permits unrestricted use, distribution, and reproduction in any medium, provided you give appropriate credit to the original author(s) and the source, provide a link to the Creative Commons license, and indicate if changes were made.

\section{References}

Boudouch O, Esrael D, Kacem M, Benadda B (2012) Estimation of soil air permeability components at a laboratory-scale pilot. Environ Technol 33:2223-2228

Farhan S, Holsen TM, Budiman J (2001) Interaction of soil air permeability and soil vapor extraction. J Environ Eng-ASCE 127:32-37

Garcia-Gerruzo F, Gomez-Lahoz C, Rodrigez-Jiminez JJ (1994) Influence of water evaporation in soil vapor extraction (SVE). Water Sci Technol 30:115-118

Huon G, Simpson T, Holzer F, Maini G, Will F, Kopinke FD, Roland U (2012) In situ radio-frequency heating for soil remediation at a former service station: case study and general aspects. Chem Eng Technol 35:1534-1544

Kauppi S, Sinkkonen A, Romantschuk M (2011) Enhancing bioremediation of diesel-fuel-contaminated soil in a boreal climate: comparison of biostimulation and bioaugmentation. Int Biodeter Biodegr 65: 359-368 
Puolanne J, Pyy O, Jeltsch U (1994) Saastuneet maa-alueet ja niiden käsittely Suomessa - Saastuneiden maa-alueiden selvitys- ja kunnostusprojekti; loppuraportti. Ministry of the Environment, Helsinki, Finland. 218 p. ISBN 951-47-4823-9 (in Finnish)

Pyy O, Haavisto T, Niskala K, Silvola M (2013) Contaminated land in Finland - report 2013. Reports of the Finnish Environment Institute 27/2013 ISBN 978-952-11-4219-2 (in Finnish)

Romantschuk M, Sarand I, Petänen T, Peltola R, Jonsson-Vihanne M, Koivula T, Yrjälä K, Haahtela K (2000) Means to improve the effect of in situ bioremediation of contaminated soil: an overview of novel approaches. Environ Pollut 107:179-185
Soares AA, Pinho MT, Albergaria JT, Domingues V, Alvim-Ferraz MCM, De Marco P, Delerue-Matos C (2012) Sequential application of soil vapor extraction and bioremediation processes for the remediation of ethylbenzene-contaminated soils. Water Air Soil Pollut 223:2601-2609

Soares AA, Albergaria JT, Domingues VF, Alvim-Ferraz MCM, DelerueMatos C (2010) Remediation of soils combining soil vapor extraction and bioremediation: benzene. Chemosphere 80:823-828

Suni S, Malinen E, Kosonen J, Silvennoinen H, Romantschuk M (2007) Electrokinetically enhanced bioremediation of creosotecontaminated soil: laboratory and field studies. J Environ Sci Health, Part A 42:277-287 